\title{
Efficient production of bisphenol-A by utilizing cation-exchange polystyrene resins that are crosslinked by naphthalene or a biphenyl unit
}

\author{
Katsuhiko Sakura $^{1,2}$ and Akihiko Tsuge ${ }^{1}$ \\ Polymer Journal (2014) 46, 82-84; doi:10.1038/pj.2013.57; published online 26 June 2013 \\ Keywords: bisphenol-A; cation-exchange resins; dry ion-exchange capacity; wet ion-exchange capacity
}

\section{INTRODUCTION}

Ion-exchange materials are well known for their utilization in the processes of water treatment, ${ }^{1-5}$ demineralization, ${ }^{6,7}$ water softening, ${ }^{8-10}$ ultra purification of water ${ }^{11,12}$ and removal of unwanted ions, ${ }^{13,14}$ as well as in chemical processing. ${ }^{15}$ One ion-exchange material is acidic sulfonated polystyrene-divinylbenzene (DVB) cation-exchange resin, which has an important role in the production of bisphenol-A by participating in an acid-catalyzed condensation reaction between phenol and acetone. Bisphenol-A is a very important raw material for the synthesis of epoxy resins and polycarbonates; thus, $>400000$ tons of bisphenol-A have recently been domestically produced. However, in the conventional polystyrene-DVB system, despite various improvements, the rate of conversion of acetone to bisphenol-A cannot be maintained owing to deterioration because of a long reaction period. ${ }^{16}$ This disadvantage could be attributed to the tiny space created by the crosslinkage of the DVB in the polystyrene-DVB system. Such a tiny space might reduce the number of sulfonated groups in the resin and induce the accumulation of by-products. Thus, to increase the conversion of acetone and to increase the space inside the polystyrene resin, divinylnaphthalene (DBN) or divinylbiphenyl (DVBP) will be used in this study as the crosslinking reagent instead of DVB to produce bisphenol-A.

\section{EXPERIMENTAL PROCEDURE}

\section{Catalysis preparation}

Copolymerization of styrene and crosslinking reagents in the emulsion, followed by sulfonation with sulfuric acid, was performed to give the desired crosslinked polystyrene resins (styrene-DVB, styrene-DVBP and styrene-DBN) according to reported methods. ${ }^{17}$

Determination of wet and dry ion-exchange capacities After $\sim 10 \mathrm{ml}$ of resin (volume $V_{1}$ ) was packed in the column, it was run with $600 \mathrm{ml}$ of $2 \mathrm{M} \mathrm{HCl}$ at space velocity (SV) $40 \mathrm{~h}^{-1}$ for $1.5 \mathrm{~h}$. Afterward, it was washed with water at SV $50 \mathrm{~h}^{-1}$ until the eluent was neutral. Additional washing with $250 \mathrm{ml}$ of $4 \% \mathrm{NaCl}$ aqueous solution at SV $17 \mathrm{~h}^{-1}$ for $1.5 \mathrm{~h}$ produced the eluent, which was titrated with $1 \mathrm{~m} \mathrm{NaOH}$ standard solution (factor $f_{1}$ ) using a mixture of methyl red and methylene blue as an indicator. When a certain volume in $\mathrm{ml}$ of $1 \mathrm{M} \mathrm{NaOH}$ standard solution $\left(V_{2}\right)$ was necessary for the titration, the wet ion-exchange capacity was obtained as follows:

$$
\text { The wet ion exchange capacity }=\frac{V_{2} \times f_{1}}{V_{1}}
$$

Approximately, $1.5 \mathrm{~g}$ of the dried resin $\left(W_{1}\right)$ swelled when $50 \mathrm{ml}$ of water was packed in the column. The column was then run with $600 \mathrm{ml}$ of $2 \mathrm{M} \mathrm{HCl}$ at SV $40 \mathrm{~h}^{-1}$ for $1.5 \mathrm{~h}$ and followed by washing with water at SV $50 \mathrm{~h}^{-1}$ until the eluent was neutral. The eluent was then washed with $250 \mathrm{ml}$ of $4 \% \mathrm{NaCl}$ solution at $\mathrm{SV} 17 \mathrm{~h}^{-1}$ for $1.5 \mathrm{~h}$, and a similar procedure to the one mentioned above was performed with $1 \mathrm{M} \mathrm{NaOH}$ standard solution (factor $f_{2}$ ) using a mixture of methyl red and methylene blue as an indicator. When a certain volume in $\mathrm{ml}$ of $1 \mathrm{M} \mathrm{NaOH}$ standard solution $\left(V_{3}\right)$ was necessary for the titration, the dry ion-exchange capacity was obtained as follows:

$$
\text { The dry ion exchange capacity }=\frac{V_{3} \times f_{2}}{W_{1}}
$$

Determination of the ratio of introduction of sulfonated groups The weight ratio of the sulfonated groups $\left(S_{\mathrm{R}}\right)$ in $1 \mathrm{~g}$ of dry resin is obtained as follows:

$$
S_{\mathrm{R}}=\frac{81.08 \times C_{\mathrm{d}}}{1000},
$$

where $C_{\mathrm{d}}$ is the dry ion-exchange capacity and 81.08 is the atomic weight of $\mathrm{SO}_{3} \mathrm{H}$.

Using the $S_{\mathrm{R}}$ value, the number of the aromatic rings $\left(P_{\mathrm{W}}\right)$ in $1 \mathrm{~g}$ of dry resin was calculated by the following equation:

$$
P_{\mathrm{w}}=\left(1-S_{\mathrm{R}}\right) \times\left(\frac{a X}{M}+\frac{100-X}{104.16}\right) \times 1000,
$$

where $a$ is the number of the aromatic ring, $M$ is the molecular weight of the crosslinking reagent and $X$ is the degree of the crosslinkage.

${ }^{1}$ Department of Applied Chemistry, Kyushu Institute of Technology, Kitakyushu, Japan and ${ }^{2}$ Environmental Techno Division, Nippon Steel \& Sumikin Eco-Tech Co., Ltd., Kitakyushu, Japan

Correspondence: Professor A Tsuge, Department of Applied Chemistry, Kyushu Institute of Technology, 1-1 Sensui-cho, Kitakyushu 804-8550, Japan.

E-mail: tsuge@che.kyutech.ac.jp

Received 28 January 2013; revised 1 May 2013; accepted 7 May 2013; published online 26 June 2013 
The ratio of added sulfonated groups $\left(N_{\mathrm{S}}\right)$ was obtained as follows:

$$
N_{\mathrm{S}}=\frac{C_{\mathrm{d}}}{P_{\mathrm{w}}}
$$

\section{Conversion of acetone to bisphenol-A}

In the presence of the wet-state sulfonated cation-exchange resin $(6.0 \mathrm{ml})$, a mixture of phenol $(18.0 \mathrm{~g}, 0.19 \mathrm{~mol})$ and acetone $(1.6 \mathrm{~g}, 0.028 \mathrm{~mol})$ with ethyl mercaptan as the reaction promoter was stirred at $70^{\circ} \mathrm{C}$ for $2 \mathrm{~h}$.

The conversion of acetone to bisphenol-A was estimated by the concentrations of acetone before and after the reactions.

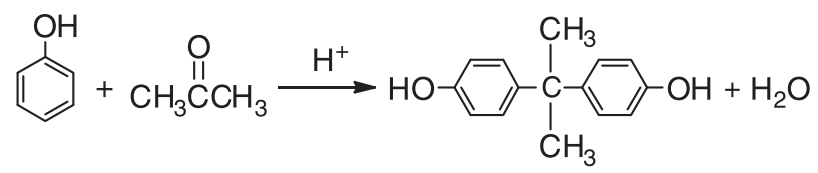

Estimation of lifetime of the cation-exchange resin catalyst After the wet-state sulfonated cation-exchange resin $(50 \mathrm{ml})$ was packed in a 1 -cm-diameter stainless reactor, the mixture of phenol, acetone and ethyl mercaptan, with a weight ratio of 1000:30:2, respectively, was continuously passed through the reactor by $50 \mathrm{ml} \mathrm{h}^{-1}$ at $70{ }^{\circ} \mathrm{C}$ to produce bisphenol-A. The lifetime of the resin was estimated by conversions after 1 day and 150 days.

\section{Measurement of the water retention capacity}

After removal of water from the resin by centrifugation, the weight of the resultant resin was measured. After this resin was dried at $105^{\circ} \mathrm{C}$ for $4 \mathrm{~h}$, its weight was again measured. From these two weights, the water retention capacity was estimated.

\section{RESULTS AND DISCUSSION}

Table 1 shows the relationship between the amount of the crosslinking reagent and the water retention capacity for the resins (styrene-DVB, styrene-DVBP and styrene-DBN).

As the amount of the crosslinking reagent increases, the water retention capacity decreases in the resins, indicating that the waterbound sites surrounding the sulfonated groups are crowded because of the increase of the crosslinkage. In comparison with styrene-DVB, lower water retention observed in the resins (styrene-DVBP and styrene-DBN) could be explained by the hydrophobic character of the crosslinking reagent.

Figure 1 shows the wet and dry ion-exchange capacities against the amount of the crosslinking reagent in the resins.

The wet ion-exchange capacity increases corresponding to increasing amounts of the crosslinking reagents because a decrease of the water retention capacity might induce increase in the wet ion-exchange capacity. On the contrary, the dry ion-exchange capacity exhibits the opposite trend when compared with increased amount of the crosslinking reagents. The aromatic rings in the main chain are preferentially sulfonated. Owing to the increase in the amount of the crosslinking reagents, the sulfonation could be hindered owing to

Table 1 The relationship between the crosslinkage and retention capacity

\begin{tabular}{lccc}
\hline & \multicolumn{3}{c}{ Crosslinkage (mol\%) } \\
\cline { 2 - 4 } Crosslinking reagent & 2.4 & 3.2 & 4.0 \\
\hline DVB & 73.2 & 66.6 & 61.0 \\
DVBP & 72.0 & 65.4 & 60.7 \\
DBN & 68.9 & 63.0 & 59.2 \\
\hline
\end{tabular}

Abbreviations: DBN, divinylnaphthalene; DVB, divinylbenzene; DVBP, divinylbiphenyl. the dense network. Thus, the dry ion-exchange capacity decreases with the increase in the amount of the crosslinking reagents because water does not have an effect.

When the same amount of crosslinking reagent is compared, both wet and dry ion-exchange capacities for styrene-DVBP and styrene-DBN are bigger than those for styrene-DVB because of the longer crosslinking reagent, which provides more space in the resin for introduction of the sulfonated groups.

Figure 2 shows the relationship between the ratio of introduction of the sulfonated group in the aromatic ring and the amount of the crosslinking reagent.

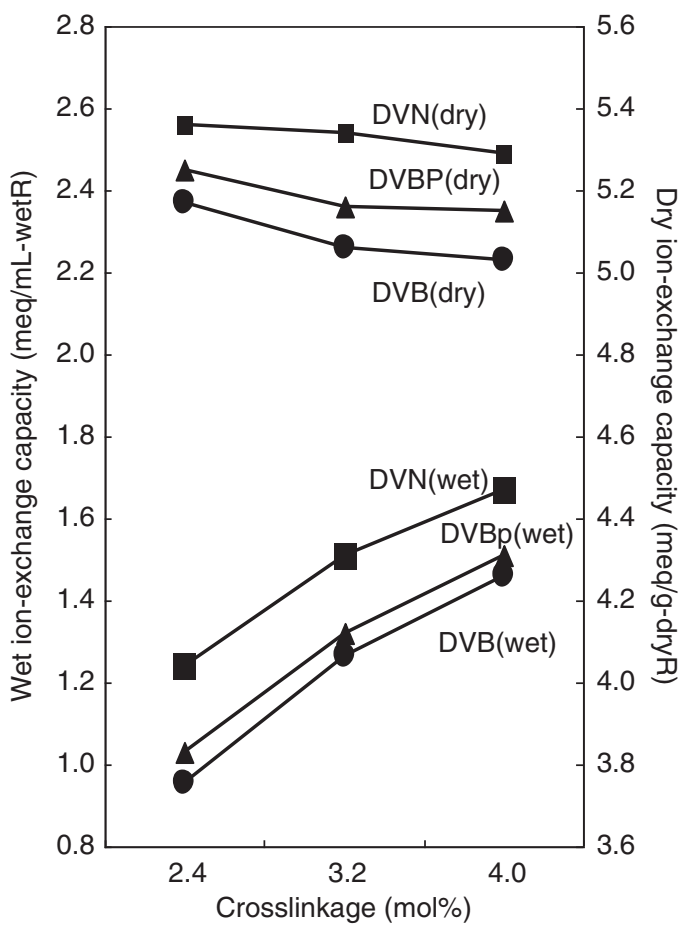

Figure 1 The relationship between wet and dry ion-exchange capacities and the amount of the crosslinking reagent.

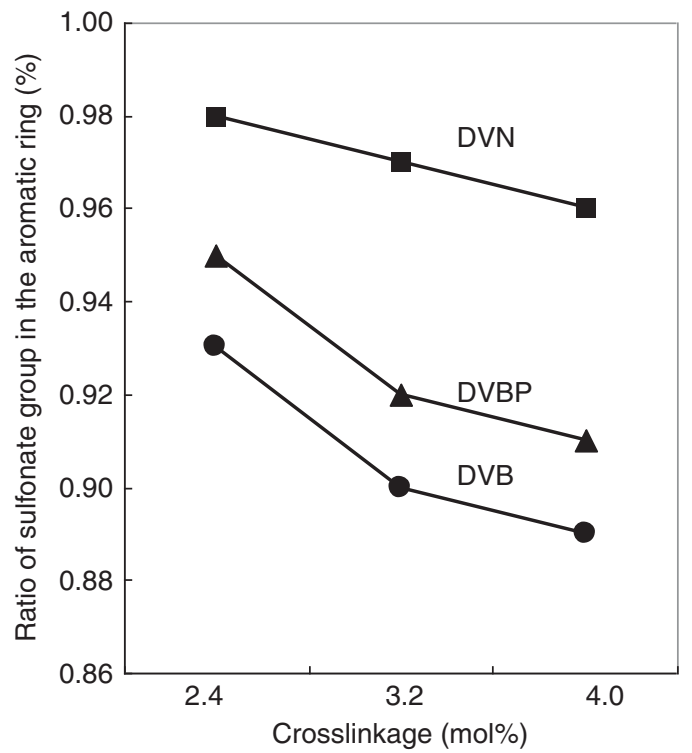

Figure 2 The relationship between the percentage of introduction of the sulfonated group and the amount of the crosslinking reagent. 


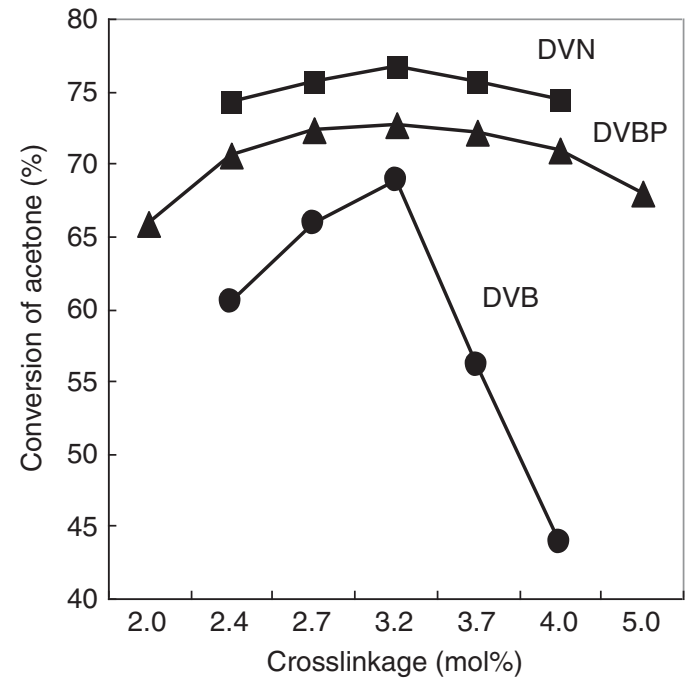

Figure 3 The conversion of acetone.

Table 2 The time course of conversion of acetone in the resins

\begin{tabular}{lcc}
\hline & \multicolumn{2}{c}{ Conversion of acetone (\%) } \\
\cline { 2 - 3 } Crosslinking reagent & 1 day & 150 days \\
\hline DVB & 89.5 & 52.6 \\
DVBP & 93.0 & 88.7 \\
DBN & 96.8 & 94.3 \\
\hline
\end{tabular}

Abbreviations: DBN, divinylnaphthalene; DVB, divinylbenzene; DVBP, divinylbiphenyl. Crosslinkage is $3.2 \mathrm{~mol} \%$.

Fewer sulfonated groups can be introduced in the aromatic rings in the resin that consists of more crosslinking reagents because of its expected thick structure. A similar trend can be observed in the case of the resin having the longer crosslinking reagent.

The relationship of the conversion of acetone and the amount of the crosslinking reagent is shown in Figure 3.

The conversion of acetone indicates a maximum of $\sim 3.2 \mathrm{~mol} \%$ of the crosslinking reagent in any resins. This phenomenon can be explained by a compromise between an increase in the number of sulfonated groups and the thickness of the structure, which deters the diffusion of phenol and acetone. Interestingly, the resins of styrene-DVBP and styrene-DBN accomplish a higher conversion compared with the resin of styrene-DVB because of an increase in the number of the sulfonated groups, as well as the space facilitating diffusion of phenol and acetone. We note that the high conversion in the resins of styrene-DVBP and styrene-DBN is still maintained even with an increase in the crosslinking reagent.

With the commercial use of resins, it is very important that their catalytic ability should be maintained for a long period; thus, the lifetimes of the cation-exchange resins of styrene-DVBP and styrene-DBN were compared with that of the cation-exchange resin of styrene-DVB.

The time course for the conversion of acetone to bisphenol-A in the resin of styrene-DVBP was examined. As described above, the highest conversion of acetone was noticed when the crosslinking reagent was at $\sim 3.2 \mathrm{~mol} \%$. This trend is similar for both 1-day and 150 -days reaction times. The conversions of acetone for both 1-day and 150-days reaction time for the resins with $3.2 \mathrm{~mol} \%$ of crosslinking reagent are summarized in Table 2.

Although the resin of styrene-DVB shows an extensive drop in the conversion of acetone at a reaction time of 150 days, a large decrease in the resins of styrene-DVBP and styrene-DBN is not observed. This finding may result in great advances in the mass production of bisphenol-A.

\section{CONCLUSIONS}

We have determined that high conversions of acetone to bisphenol-A can be obtained even after 150 days of reaction time for styrene-DVBP and styrene-DBN resins. This maintenance of a high conversion for a long reaction time is due to the large space inside the structure of the resins that can be increased by employing DBN or DVBP as the crosslinking reagents instead of DVB. We note that the newly developed resins of styrene-DVBP and styrene-DBN described herein should provide great improvements to the large-scale production of bisphenol-A in industry because of the high efficiency of the conversion rate of acetone that can be maintained for a long time period.

1 Neale, P., Mastrup, M., Borgmann, T. \& Schafer, A. Sorption of micropollutant estrone to a water treatment ion exchange resin. J. Environ. Monit. 12, 311-317 (2010).

2 Tesser, R., Di Serino, M., Casale, L., Carotenuto, G. \& Santacesaria, E. Absorption of water/methanol binary system on ion-exchange resins. Can. J. Chem. Eng. 88, 1044-1053 (2010)

3 Pakzadeh, B. \& Batista, J. Chromium removal from ion-exchange waste brines with calcium polysulfide. Water Res. 45, 3055-3094 (2011).

4 Ye, L., You, H., Yao, J. \& Su, H. Water treatment technologies for perchlorate. Desalination 298, 1-12 (2012).

5 Morel, A., Zuo, K., Xia, X., Wei, J., Luo, X., Liang, P. \& Huang, X. Microbial desalination cells packed with ion-exchange resin to enhance water desalination rate. Bioresour. Technol. 118, 43-48 (2012).

6 Atia, A., Donia, A. \& Elwakeel, K. Selective separation of mercury(II) using a synthetic resin containing amine and mercaptan as chelating groups. React. Funct. Polym. 65 267-275 (2005).

7 Sharma, Y., Srivastava, V., Singh, V., Kaul, S. \& Weng, C. Nano-adsorbents for the removal of metallic pollutants from water and wastewater. Environ. Technol. 30, 583-609 (2009).

8 Entezari, M. \& Tahmasbi, M. Water softening by combination of ultrasound and ion exchange. Ultrason. Sonochem. 16, 356-360 (2009).

9 Apell, J. \& Boyer, T. Combined ion exchange treatment for removal of dissolved organic matter and hardness. Water Res. 44, 2419-2430 (2010).

10 Ghergheles, C., Ghergheles, V., Romocea, T., Roman, M., Pantea, E., Ion, M. \& Iovi, A. Softening of waste geothermal water using ion exchange resins for environment protection. J. Environ. Prot. Ecol. 13, 1553-1559 (2012).

11 Buragohain, P., Gill, W. \& Cramer, S. Novel resin-based ultrapurification system for reprocessing IPA in the semiconductor industry. Ind. Eng. Chem. Res. 35, 3149-3154 (1996).

12 Carmona, M., Valverde, L., Perez, A., Warchol, J. \& Rodriguez, F. Purification of glycerol/water solutions from biodiesel synthesis by ion exchange: sodium removal Part I. J. Chem. Technol. Biotechnol. 84, 738-744 (2009).

13 Soliman, E., Ahmed, S. \& Fadi, A. Removal of calcium ions from aqueous solutions by sugar cane bagasse modified with carboxylic acids using microwave-assisted solvent-free synthesis. Desalination 278, 18-25 (2011).

14 Kumar, R., Jain, S., Misra, R., Kachchwaha, M. \& Khatri, P. Aqueous heavy metals removal by adsorption on beta-diketone-functionalized styrene-divinylbenzene copolymeric resin. Int. J. Environ. Sci. Technol. 9, 79-84 (2012).

15 Watson, K., Farre, M. \& Knight, N. Strategies for the removal of halides from drinking water sources, and their applicability in disinfection by-product minimization. J. Environ. Manage. 110, 276-298 (2012).

16 JeraBek, K. Distribution and catalytic activity of sulfonic acid groups in organic ion-exchangers. J.Polym. Sci. A Polym. Chem. 18, 65-67 (1980).

17 Hayashi, K. \& Tsutsumichi, I. Japanese Patent, 165937 A (2009). 